\title{
Ação comunicativa na gestão de um serviço privatizado de água e esgotos: uma avaliação em Cachoeiro de Itapemirim (ES)
}

\author{
Marluce Martins de Aguiar \\ Instituto Federal do Espirito Santo \\ Léo Heller \\ Universidade Federal de Minas Gerais \\ Elza Machado de Melo \\ Universidade Federal de Minas Gerais
}

\begin{abstract}
Este artigo discute o processo de participação social na gestão do serviço de abastecimento de água e esgotamento sanitário do município de Cachoeiro de Itapemirim (ES). Para tanto, apoia-se no conceito de democracia deliberativa de Jürgen Habermas, entendido como a institucionalização dos processos discursivos de formação da opinião e da vontade. Foram realizadas pesquisas documentais, entrevistas com atores-chave e grupos focais com a população. Constatou-se que, na atuação do Conselho Municipal de Saneamento e das audiências públicas da agência municipal de regulação, prevalecem os imperativos sistêmicos mediados pelo dinheiro e pelo poder administrativo em detrimento da possibilidade de formação política da vontade e da opinião, próprios do mundo da vida. Conclui-se que as formas de gestão ainda são distantes do ideal da democracia deliberativa, produzindo-se o que Habermas denomina de "colonização do mundo da vida".
\end{abstract}

Palavras-chave: gestão de serviços de abastecimento de água e esgotamento sanitário; participação social; teoria da ação comunicativa; democracia deliberativa.

Acción comunicativa en la gestión de un servicio privatizado de abastecimiento de agua y saneamiento: una evaluación en Cachoeiro de Itapemirim (ES)

En este artículo se analiza el proceso de participación en la gestión de servicios de abastecimiento de agua y saneamiento en el municipio de Cachoeiro de Itapemirim-ES. Para ello, se apoya en la concepción de la democracia deliberativa de Jürgen Habermas, entendida como la institucionalización de los procesos discursivos de formación de la opinión y de la voluntad. Se realizó una investigación documental, entrevistas con actores claves y grupos focales con representantes de la población. Se

Artigo recebido em 14 dez. 2011 e aceito em 17 ago. 2012. Os autores agradecem ao CNPq e à Funasa pelo apoio financeiro à pesquisa. 
encontró que, en la actuación del Consejo de Saneamiento de la Ciudad y en las audiencias públicas de la agencia de regulación municipal, los imperativos sistémicos prevalecen mediados por el dinero y el poder administrativo sobre la posibilidad de la formación de la voluntad política y de la opinión, propio del mundo de la vida. Se concluyó que las formas de gestión aún están lejos del ideal de la democracia deliberativa, produciendo lo que Habermas llama la "colonización del mundo de la vida".

Palabras clave: gestión de servicios de abastecimiento de agua y saneamiento; participación social; teoría de la acción comunicativa; democracia deliberativa.

Communicative action in the managment of a privatized water and sanitation services: an assessment in Cachoeiro de Itapemirim (ES)

This article discusses the social participation in water and sanitation services in Cachoeiro de Itapemirim, Espírito Santo, Brazil. The theoretical background used was Jürgen Habermas' deliberative democracy, understood as the institutionalization of discursive processes of opinion and will-formation. Documentary research were performed, interviews with key stakeholders and focus groups with the population. It was found that in the actions of the City Council Sanitation and public hearings of the municipal regulation agency's, systemic imperatives mediated by money and administrative power prevail over the possibility of the formation of political will and opinion, own the world's life. It is concluded that the forms of management are still far from the ideal of deliberative democracy, producing what Habermas calls the "colonization of the lifeworld".

KEY WORDS: water and sanitation management; social participation; communicative action theory; deliberative democracy.

\section{Introdução}

As políticas de saneamento básico no Brasil, em que pesem os avanços alcançados em relação a alguns indicadores, como a cobertura urbana pelo abastecimento de água, ainda não foram capazes de resolver as desigualdades no acesso aos serviços e soluções individuais. Isso pode ser constatado quando se avaliam os dados em relação às regiões do Brasil, às faixas de renda e aos demais serviços, como os de esgotamento sanitário e manejo de resíduos sólidos (Britto, 2004; Rezende e Heller, 2008).

Por outro lado, quanto ao ideário de uma gestão democrática, pode-se constatar que existe no setor o que Rezende e Heller (2008) definem como "passivo de democratização", uma vez que a sociedade civil em geral tem estado ausente das decisões e definições das políticas. Esse deficit de participação, tanto na política pública quanto na gestão dos serviços, ainda persiste, como demonstra o longo percurso histórico do setor (Heller, Rezende e Heller, 2007). Assim, a realidade brasileira é ainda marcada por um distanciamento entre o Estado e a sociedade civil, com o predomínio de relações autoritárias e conservadoras, reveladas tanto no plano da política institucional quanto na fragilidade do tecido associativo (Jacobi e Pinho, 2006).

No que se refere aos modelos de gestão de saneamento adotados na América Latina e particularmente no Brasil, o enfoque na especialização e a tradição hierárquica contribuem para 
o desenvolvimento de instituições fechadas à avaliação e ao controle do usuário e cidadão. Isto vem criando um distanciamento em relação a eles, tanto da perspectiva do reconhecimento de seus direitos, como de seus deveres e responsabilidades (Castro e Lacabana, 2005).

Não obstante as constatações das ainda fragmentárias experiências de gestão participativa, diversos autores têm trazido à discussão a importância da superação das barreiras socioinstitucionais e da necessidade da criação de esferas públicas de participação cidadã para a formulação e o controle das políticas públicas (Gutmann e Thompson, 2007; Heller e Castro, 2007; Santos e Avritzer, 2005).

Em alguns setores das políticas públicas, como na saúde, mecanismos institucionais formais de participação já se fazem presentes, por meio de conselhos e conferências, desde a década de 1980. Também na área ambiental, as audiências públicas para discussão de projetos de significativo impacto são instrumentos previstos legalmente desde 1981. Os conselhos de educação e meio ambiente, os comitês de bacia e os conselhos de planos diretores urbanos, entre outros, são exemplos de mecanismos institucionais de participação que, embora possam ainda guardar certa distância de um processo substantivamente democrático, podem se constituir em inspiração para a política e a gestão do saneamento (Heller, Rezende e Heller, 2007).

Algumas experiências exitosas de participação na formulação de políticas públicas revelam importantes possibilidades de processos interativos entre a sociedade e o Estado. Um exemplo é o Orçamento Participativo adotado por diversas administrações municipais brasileiras. Em relação à área de saneamento, o processo de participação popular revelou-se importante fator para o alcance da eficiência e performance em relação à universalização dos serviços em Porto Alegre, por exemplo (Fung, 2006; Viero, 2003).

Uma possibilidade para ampliação dos debates sobre a democratização do setor surge com a aprovação, da Lei no 11.445 (Brasil, 2007), que estabelece as diretrizes nacionais para o saneamento básico. Essa Lei prevê, ainda que timidamente, a necessidade do controle social. Essa dimensão sociopolítica ganha especial relevância, uma vez que a referida lei estabelece a necessidade de os titulares ${ }^{1}$ dos serviços, em geral os municípios, elaborarem e implementarem suas políticas de saneamento. Tais políticas deverão ser formuladas por meio da elaboração dos planos municipais de saneamento e do estabelecimento de mecanismos de controle social, constituindo-se, assim, numa importante oportunidade de se buscarem formas participativas, que incluam a população e os demais setores institucionais, nos debates e formulações.

Diversos autores, como Avritzer (2005), Dagnino (2004), Lüchmann (2002), Batista e Melo (2011), Santos e Avritzer (2005), Tatagiba (2002), Tenório e Marques Filho (2006), vêm trabalhando as discussões conceituais e a avaliação da participação social nas políticas públicas do Brasil. A discussão conceitual do tema vem apontando seu caráter polissêmico,

\footnotetext{
${ }^{1}$ Entende-se como sendo do município a titularidade para a gestão, execução e eventual concessão dos serviços de saneamento básico (Alochio, 2007) e a formulação da respectiva política pública de saneamento básico.
} 
adquirido ao longo das últimas décadas, podendo estar associado tanto aos discursos neoliberais, em geral representando obediência e respaldo a decisões previamente tomadas, quanto a correntes que o entendem numa perspectiva de emancipação e de busca da cidadania. Por outro lado, os estudos que trazem as experiências empíricas de espaços públicos de participação podem contribuir para a análise de suas possibilidades e limites e de apontar direções para políticas públicas mais democráticas.

Este artigo traz a discussão de um estudo sobre a participação social na gestão dos serviços de água e esgoto no município de Cachoeiro de Itapemirim, Espírito Santo. O marco referencial utilizado foi a teoria da ação comunicativa de Jürgen Habermas, em particular, a democracia deliberativa, entendida como a institucionalização de processos discursivos de formação da opinião e da vontade. Um modelo de gestão participativa pressupõe um processo democrático de cooperação e de caráter pedagógico, como um processo de aprendizado estabelecido de forma reflexiva, tal como propõe Habermas (1997), de modo que a população, ao se conscientizar de seu papel político-deliberativo, possa influenciar de forma ativa em sua formulação, execução e avaliação. Isso, por sua vez, requer relações sociais que possibilitem o envolvimento dos afetados pelas decisões, que assim se tornam compartilhadas.

\section{A democracia deliberativa}

À diferença da democracia eleitoral, inspirada no agir instrumental, o modelo de democracia deliberativa, tal como proposto por Habermas, inspira-se no agir comunicativo e, no lugar de escolha entre alternativas dadas, propõe a participação efetiva dos envolvidos na própria formulação das alternativas, a partir de suas necessidades e preferências. Os resultados alcançados dessa forma não se reduzem a uma simples agregação de preferências, mas seriam sustentados de forma legítima por uma troca pública de razões (Habermas, 1997).

Segundo Habermas, normas e leis adquirem validade ao passarem pelo crivo discursivo, processo de argumentação em que os envolvidos, livres de constrangimentos e com chances iguais de proferirem suas considerações, sentimentos, desejos, recomendações, buscam o consenso sobre o que deve ser feito. A institucionalização de tais processos discursivos de formação da opinião e da vontade constitui-se como princípio fundamental da democracia deliberativa. Em outras palavras, os procedimentos é que são os responsáveis pela legitimação das normas e leis (Avritzer, 2009; Marques, 2009).

A efetivação concreta do princípio de democracia se faz pelo sistema representativo, isto é, o parlamento, firmemente ancorado nas redes comunicacionais da esfera pública, que, por sua vez, tem como substrato as organizações da sociedade civil. Como toda estrutura do mundo da vida, a esfera pública é reproduzida pela ação comunicativa e se refere ao espaço social por ela gerado.

Da mais simples interação, esse espaço pode se expandir, incorporando sucessivamente novos atores, generalizando-se, distanciando-se cada vez mais dos contextos específicos, vinculando- 
se, portanto, à cidadania em geral, mas sem perder o eco das experiências individuais (Melo, 2008:S31).

O debate público assim construído dramatiza os problemas e necessidades dos atores sociais no seu mundo da vida, suas proposições penetram as comportas do Estado e, tratadas pelas instâncias institucionalizadas do complexo representativo, transformam-se em soluções aprovadas na forma de leis, políticas, programas e projetos: em poucas palavras, é poder comunicativo que se transforma em poder administrativo, pois "Somente após a 'luta por reconhecimento', desencadeada publicamente, os interesses questionados podem ser tomados pelas instâncias políticas responsáveis, introduzidas nas agendas parlamentares, discutidos e, eventualmente, elaborados na forma de propostas impositivas" (Habermas, 1997:47, grifo do autor).

Numa sociedade marcada pelo pluralismo e de alto nível de complexidade, Habermas (1997) traz, em sua teoria, a preocupação de estabelecer a dimensão normativa por questionar, de um lado, a redução política a uma lógica individualista e competitiva e, de outro, a ideia exacerbada de uma vontade coletiva robusta e integrada de um povo. O equilíbrio entre essas posições polares, ele encontra pela articulação entre ambas, isto é, dos conceitos de cidadania e de soberania popular. De acordo com ele, "neste modelo a busca cooperativa empreendida por cidadãos deliberativos, por soluções para problemas políticos, substitui a ideia da agregação de preferências de cidadãos privados ou da autodeterminação coletiva de uma nação eticamente integrada" (Habermas, 2008:11). Dessa forma, a deliberação constitui-se um processo de aprendizagem, que se estabelece de maneira reflexiva. Assim, diz respeito a todo cidadão a quem as políticas públicas estão direcionadas, não se restringindo aos especialistas ou técnicos.

A democracia deliberativa vem sendo reconhecida como processo útil para propósitos críticos, especialmente pela possibilidade de "iluminar deficiências nos arranjos deliberativos existentes" (Bohman, 2009:36), como conselhos gestores e audiências públicas e outros arranjos institucionais, revelando uma crescente preocupação com pesquisas relacionadas à prática deliberativa (Batista e Melo, 2011; Della Porta, 2005; Grönlund, Setäla e Herne, 2010; Fishkin et al., 2010; Neblo, 2005; Rist et al., 2007; Vizeu e Bin, 2008).

A gestão democrática do saneamento, nos moldes da proposta habermasiana, que possibilitaria valorizar a "voz" dos diversos atores envolvidos, desde a formulação da política até a avaliação dos resultados, é um requisito tanto para atender aos direitos dos cidadãos como para ampliação da democracia. Nos processos de discussão, os cidadãos encontram oportunidades para expor seus pontos de vista, reconhecer os mal-entendidos, expressar suas aspirações e necessidades, repensar valores e normas, expandir seu conhecimento tanto a respeito de si quanto do que pode ser melhor para seus concidadãos e contribuir com sua cultura e conhecimentos para um mútuo aprendizado e busca de soluções que possam melhorar as suas condições de vida. 


\section{Procedimentos metodológicos}

A presente pesquisa foi submetida ao Comitê de Ética em pesquisa da Universidade Federal de Minas Gerais (UFMG) e aprovada em 8 de maio de 2008.

As fontes primárias de dados foram as entrevistas semiestruturadas individuais e os grupos focais. Em consonância com o referencial teórico, o uso das entrevistas permite "a compreensão dos mundos da vida dos entrevistados e de grupos sociais especificados" (Gaskell, 2002:65). Em suas experiências como técnicos, gerentes, representantes dos poderes Executivo e Legislativo e da sociedade civil, os entrevistados contribuíram de forma expressiva para a compreensão das relações estabelecidas na política e gestão dos serviços de abastecimento de água e esgoto do município.

Na pesquisa qualitativa, diferentemente da pesquisa quantitativa, a seleção dos sujeitos não demanda amostra estatística representativa da população (Gaskell, 2002). Interessam, antes, a abrangência e o aprofundamento da compreensão "capaz de refletir a totalidade nas suas múltiplas dimensões" (Minayo, 2006:197). Foram realizadas 10 entrevistas individuais (quadro seguinte) e quatro grupos focais.

A seleção dos sujeitos para as entrevistas individuais foi do tipo intencional (Thiollent, 1987), pois importava aqueles que detêm ou detinham maior conhecimento sobre o objeto da pesquisa e desempenham ou desempenharam papel relevante para a gestão dos serviços de abastecimento de água e esgoto por um maior período de tempo.

Os entrevistados foram previamente selecionados, segundo a entidade ou instituição representativa, em contatos realizados em dezembro de 2008. Tal procedimento consubstanciou-se em importante suporte para identificação da relevância do papel de cada um, além de propiciar um entendimento de como estavam estruturadas a política e a gestão dos serviços no município.

Quadro

Número de entrevistados por entidade ou instituição e sigla de identificação

\begin{tabular}{|c|c|c|}
\hline Instituição & $\begin{array}{c}\text { № de } \\
\text { participantes }\end{array}$ & Siglas de identificação \\
\hline Agência (Agersa) & 1 & RA \\
\hline Citágua (Foz do Brasil) & 2 & $\mathrm{RCl}$ \\
\hline Câmara Municipal & 1 & $\mathrm{RCM}$ \\
\hline Conselho Municipal de Saneamento (Comusa) & 2 & RCO1 e RCO2 \\
\hline Conselho Municipal de Saúde & 1 & RCS \\
\hline Federação dos Movimentos Populares de Cachoeiro de Itapemirim (Famopoci) & 1 & RF \\
\hline Poder Executivo & 1 & RE \\
\hline Secretaria Municipal de Meio Ambiente & 1 & RMA \\
\hline
\end{tabular}

Fonte: Elaboração dos autores. 
Um pré-teste das entrevistas individuais foi realizado em março de 2008, para avaliação da adequação e necessidade de complementações das perguntas. As entrevistas ocorreram no período de 11 a 17 de março de 2009 e foram gravadas com a autorização prévia dos entrevistados.

Os grupos focais abrangeram distintamente pessoas de bairros de classe de rendas baixa e média, promovendo a homogeneidade no mesmo grupo e a heterogeneidade entre grupos. O objetivo dessa distinção foi o de captar as diferentes percepções da população com faixas de renda diferenciadas. Para a seleção dos participantes, foram estabelecidos os critérios: atuar como liderança no bairro (formal ou informal) e ser morador do município há mais de 10 anos. A seleção dos bairros foi estabelecida junto à equipe de Estratégia da Saúde da Família (ESF), que tem sua estruturação dividida por setores socioeconômicos. Foram realizados dois grupos focais no bairro Gilson Carone, de perfil de baixa renda (nove e 12 participantes), e dois no bairro Paraíso, com perfil de renda média (oito e 10 participantes).

Foi feita também coleta de dados em leis, decretos, edital de concorrência pública, contrato de concessão, atas de reuniões do Comusa, relatórios anuais da Agersa e planejamento estratégico da Citágua (Foz do Brasil).

Para a análise interpretativa dos dados das entrevistas e documentos coletados, foram percorridas as etapas sugeridas por Minayo (2006), que prevê as fases de pré-análise, exploração do material, seleção de categorias e análise final dos dados fundamentada no marco teórico utilizado.

\section{A participação social na gestão de abastecimento de água e esgotos de Cachoeiro de Itapemirim}

O município de Cachoeiro de Itapemirim está localizado ao Sul do Espírito Santo e apresenta uma população de 180.984 habitantes (IBGE, 2010). Trata-se do principal centro econômico dessa região do estado. Destaca-se em sua economia o setor de extração e beneficiamento de rochas, principalmente mármore e granito, sendo um centro internacional de rochas ornamentais. Na indústria sobressai a produção de cimento, calçados e laticínios.

O município integra a principal bacia hidrográfica do sul do estado, a do rio Itapemirim. Seu Índice de Desenvolvimento Humano (IDH) do ano 2000 era de 0,77, sendo o do Espírito Santo, de 0,767, considerados de médio desenvolvimento (IJSN, 2004).

A concessão dos serviços de abastecimento de água e esgoto a uma empresa privada ocorreu no ano de 1998. A Citágua — Águas de Cachoeiro S.A. —, empresa que se compunha à época do Grupo Águia Branca (acionista majoritário) e do Grupo Cepemar (Costa, 2005), assumiu a concessão dos serviços após a participação em um processo de concorrência

pública. Até então, operava o Serviço Autônomo de Água e Esgoto (Saae), uma autarquia municipal. Os serviços, à época da privatização, encontravam-se em situação bastante precária. 
Havia faltas constantes de abastecimento de água (principalmente nas regiões mais elevadas) e baixo índice de cobertura de esgotamento sanitário, em especial no que se refere à falta de tratamento (somente 5\% eram tratados). Os esgotos eram lançados no rio Itapemirim e seus afluentes. Havia ainda elevado índice de perdas, precariedades técnico-operacionais e de equipamentos (Costa, 2005).

A concessão dos serviços a uma empresa privada, bastante estimulada pelo governo Fernando Henrique Cardoso (Britto, 2004), foi motivada pela falta de recursos próprios da Prefeitura e de financiamentos públicos para investimentos:

Eu era prefeito de Cachoeiro de Itapemirim e recebia constantemente reclamações de falta de água praticamente em todo o município e no interior. Além disso, o problema de esgoto era terrível. O esgoto era jogado em vários córregos, como Amarelo, Ilha da Luz, Aeroporto... E eu cansei de ir a Brasília e tentar recursos para fazer o esgoto captado e um novo serviço de água pra Cachoeiro, que tinha sido ainda do tempo de João Goulart. Quer dizer, mais de 40 anos. Tava obsoleto, quer dizer, Cachoeiro ia entrar numa dificuldade histórica. Depois, descontados todos os pedidos que eu fiz, eu fui aconselhado pelo próprio governo federal para fazer do Serviço de Água e Esgoto de Cachoeiro de Itapemirim um serviço que não fosse mais... vamos dizer assim... público [RE].

O início das atividades da Citágua deu-se em 14 de julho de 1998. O prazo de concessão previsto era de 30 anos, prorrogável por mais 20 anos, caso houvesse interesse de ambas as partes. Esse prazo foi alterado para 37 anos, pelo sétimo Termo Aditivo ao Contrato de Concessão, em junho de 2006 (Agersa, 2006).

Os serviços prestados pela Citágua incluem as atividades de captação, tratamento e distribuição de água, coleta e tratamento de esgoto, operação, conservação, manutenção, ampliação e cobrança direta aos clientes dos serviços (Citágua, 2008). O contrato de concessão não inclui a zona rural do município.

A empresa foi vendida em julho de 2008 para a empresa Odebrecht, que atua no desenvolvimento e administração de projetos de infraestrutura, com foco em concessões e parcerias público-privadas.

A Política Municipal de Saneamento (PMS), instituída pela Lei no 4.797/1999 (Cachoeiro de Itapemirim, 1999a), fundamenta-se na concepção do saneamento como um serviço público essencial à proteção ambiental e à saúde pública. Para sua formulação, implementação e controle, a Lei prevê o Sistema Municipal de Saneamento (Simsa), assim composto: Conselho Municipal de Saneamento (Comusa); Secretaria Municipal de Meio Ambiente e Desenvolvimento Sustentável; Agência Municipal de Regulação dos Serviços Públicos Delegados de Cachoeiro de Itapemirim (Agersa); organizações da sociedade civil afins; autarquias e secretarias afins do município, definidas em ato do Poder Executivo.

As instâncias formais de participação previstas pela PMS são o Comusa e as audiências públicas da Agersa. O Comusa é o órgão superior do Simsa, possui caráter deliberativo e 
sua composição, alterada pelo Decreto nº 17.253/2007 (Cachoeiro de Itapemirim, 2007), é formada pelos representantes de: Secretarias Municipais de Meio Ambiente; Planejamento e Orçamento; Saúde; Desenvolvimento Social; Obras e Serviços Urbanos; Controladoria Geral do Município; Procuradoria Geral do Município; Agersa; Câmara Municipal de Cachoeiro de Itapemirim; Câmara de Dirigentes Lojistas; Associação de Moradores de Bairros da cidade; Citágua (Foz do Brasil); entidade ambientalista e trabalhadores na área de saneamento.

\subsection{A Política Municipal de Saneamento e a participação no Comusa}

A PMS tem por finalidade regular a ação do Poder Público Municipal, sua relação com os cidadãos e instituições públicas e privadas, assegurando a saúde da população e a salubridade do meio ambiente urbano e rural, a serem executados pelo Simsa. Contém importantes dispositivos, nos quais está prevista a articulação com os demais setores, instituições e a sociedade (Cachoeiro de Itapemirim, 1999a). O que se constatou, no entanto, é a presença incipiente do poder público na definição da política, no que se refere às ações relativas ao abastecimento de água e esgotamento sanitário, que vêm sendo norteadas pela própria prestadora, Citágua (Foz do Brasil), e pela Agersa, como revelado no trecho da fala do representante do Comusa:

E aí o município também fica... Pô, cê tá fazendo aqui, tá bom demais, prá que que eu vou me preocupar? Agora, podia ser uma coisa discutida né? Podia ser muito mais eficiente. Infelizmente não dá prá ser dessa maneira. [...] u acho que na verdade, porque o saneamento não pode ser uma coisa isolada de uma empresa, você entendeu? Ele tem que ser um conjunto de ações prá dar certo, prá dar certo, entre município, estado e as companhias que operam, seja estadual ou municipal [RCO2].

A percepção de que a política de saneamento não se efetiva na prática foi expressa também nos grupos focais:

Eu acho que na realidade é o compromisso da nossa cidade não somente com o povo. Principalmente cumprir as determinações que são impostas a ela. Que hoje não são cumpridas. Eu acho que a partir do momento que existe a lei no papel, se aquilo ali for realmente... Porque no Brasil muitas vezes é assim: a lei tá no papel, mas ela não é cumprida na realidade. Se cumprisse o prometido, o que se determina a lei, com certeza vai... vai ser suficiente [P7P2]. ${ }^{2}$

\footnotetext{
${ }^{2}$ A identificação dos participantes P dos grupos focais (número, sigla dos bairros Paraíso: P e Gilson Carone: GC e número do grupo).
} 
Isto dificulta a participação e faz com que os usuários fiquem confusos a respeito das responsabilidades e atribuições de cada órgão ou instituição, acarretando também prejuízos ao atendimento de suas demandas e necessidades:

Eu fui até a Citágua e até a Prefeitura também, mas só que um joga pro outro. Eu tô até com um papel lá em casa falando que a Prefeitura já pagou pra Citágua... é... o negócio ali é da Citágua... e a Citágua vai ali e fala que é nascente. Um esgoto fedorento, água preta vem lá do Alto Coramare... E fala que é nascente. (...) na realidade tem alguém que comanda, eles têm medo até de divulgar. Porque eles têm medo de ser cobrado [P4P1].

A análise do funcionamento do Comusa permitiu constatar que o seu funcionamento vem sendo bastante limitado. Os principais fatores são discutidos a seguir.

\subsubsection{A assimetria}

Um dos principais fundamentos da democracia deliberativa é a garantia da simetria, que assegure a igualdade de condições para acordos democraticamente formados (Habermas, 1997; Bohman, 2009). No Comusa, essas condições não são asseguradas, como demonstra trecho da manifestação de um dos conselheiros:

Pois é, por isso é que eu estou falando com você, porque na verdade é o seguinte: hoje, por exemplo, a maioria absoluta do conselho ele é entendeu, do poder público, ele é do poder público (...) Porque a grande maioria absoluta são secretário, diretor, diretor da própria Concessionária, então, eu não sei, sinceridade, te especificar, qual o espaço que a gente tem pra apresentar propostas, ideias [RCO2].

Trata-se nesse caso de uma assimetria representativa, condição inibidora do entendimento próprio da ação comunicativa. Habermas (2010), citado por Pinto (1996:138), comenta a necessidade da "garantia da simetria entre os diversos participantes num processo comunicativo, para que os atores sociais possam expressar suas pretensões de validade com igual liberdade".

Tatagiba (2002) comenta que, em face das características de nossa cultura política, o princípio da paridade tende a se converter em vantagens para o governo, que podem ter como consequência acentuados desequilíbrios no processo decisório. Cabe ressaltar que, em princípio, quem opera no interior do Estado dispõe de condição privilegiada em relação à possibilidade de acesso a informações e também quanto à qualificação para uma melhor representação. De acordo com Fung e Wright (2001), as posições desiguais de poder dessas instituições podem se constituir numa das principais fragilidades em relação às possibilidades deliberativas. 


\subsection{2 [Des]qualificação da representação: “Eu num posso tá falando só sim e não, lá pro Conselho"}

Para o pleno exercício da representação no Conselho, é essencial que os representantes sejam bem informados e qualificados. Verificou-se falta de qualidade na participação, devido à falta de informação e de conhecimento quanto aos principais instrumentos da política de saneamento e também quanto às atribuições dos representantes:

Ah, tá muito fraca... a minha participação tinha que ser melhor. Eu teria que... eu teria que ir lá fazer com que... com que acontecer mesmo, entendeu? (...) Não conheço a lei, mas tem. Tem a lei, mas eu não conheço não... essa entrevista tá sendo boa, que eu vou buscar isso tudo aí daqui a pouco... essa informação. É, porque.... às vezes eu tô fazendo parte do Conselho e eu num posso tá falando só sim e não lá pro Conselho. Eu tenho que dar tipo a minha opinião pra eles também [RCO1].

A ele não é dado capacitação, a ele não é dado... Quer dizer: nós tamos com esse problema no Conselho. (...) Nível de participação social, porque o conselheiro, sem ele ter noção, capacitação de... de participação e controle e fiscalização mesmo, no Conselho ele não vai ter noção do que é ser conselheiro. Ele vai tá ali voando, sem saber o que que ele tem que fazer [RCS].

Integrante do Comusa comentou, após entrevista, que se sentia inibido devido à presença de "doutores", reconhecendo sua fraca atuação diante do Conselho. Este fato tem sido constatado por autores como Batista e Melo (2011), Pinto (1996) e Tatagiba (2002). Apoiando-se no postulado habermasiano de colonização do mundo da vida, pode-se dizer que há uma tendência no funcionamento dos conselhos em transformar problemas práticos (que demandam uma solução política negociada) em problemas técnicos. Dessa forma, a consequente retenção dos saberes científicos e tecnológicos na mão de especialistas acaba por gerar uma elite afastada dos cidadãos comuns, que por sua vez se removem dos processos de deliberação, na crença de que "eu deixo isso para aqueles que conhecem o assunto...". A elite, por sua vez, crê que esses assuntos devem ser exclusivamente técnicos (Thomassen, 2010). Esse modo de agir pode ser constatado em trechos da intervenção do representante da Citágua registrado na ata da reunião do Comusa de 27 de julho de 2009: “[...] O próprio Contrato já é um plano, plano que precisa se adequar e é um assunto muito técnico, é preciso haver opiniões de pessoas técnicas capacitadas para tal, dando assim o suporte necessário". Macedo (1993:40) comenta a esse respeito, respaldada em Habermas:

(...) A tematização de questões relevantes é impedida pela transformação das decisões políticas em técnicas. Subsumindo todas as dimensões da atividade humana à atividade com relação a fins, cria-se um fórum técnico de discussão de todas as questões postas no mundo vivido. Como as regras do discurso técnico não são dominadas por todos os cidadãos, aqueles que não são capazes de utilizar a linguagem técnica privilegiada são alijados do processo de comunicação. 
Tatagiba (2002) comenta a necessidade de qualificação dos representantes dos conselhos sem que se tenham como consequência a elitização e a burocratização da participação. Em outras palavras, a qualificação dos representantes é necessária para que sejam informados e conheçam as estruturas de funcionamento institucionais sem que, no entanto, sejam incorporados à teia burocrática (Gohn, 2006).

Essa preocupação é muito importante, uma vez que, sendo os conselhos espaços de consenso intersubjetivo, é essencial considerar os saberes locais, valores e concepções de vida e as práticas dos movimentos sociais, que trazem contribuições do seu mundo da vida:

E olha que quando você for pra sociedade, a sociedade é capaz de apresentar proposta inteligente capaz de ser benéfica para o saneamento de uma maneira muito mais útil do que às vezes a própria ideia de alguns prefeitos, vereador [RCO2].

Sem isso, os conselhos se tornariam meramente burocráticos e técnicos e funcionariam nos moldes da ação estratégica.

\subsubsection{Os assuntos: "basicamente de discutir tarifas" e as interferências políticas}

A partir das entrevistas e leitura das atas, constatou-se que os assuntos tratados no conselho relacionam-se predominantemente com o reajuste de tarifa ou ajustes no contrato com a Citágua. Conforme preocupação explicitada pelo diretor da Agersa (Ata da reunião do Comusa de 27 de julho de 2009), “(...) O Comusa precisa se envolver e não somente votar quando há aumento da tarifa". Esse é outro fator que limita o funcionamento do conselho:

(...) Eu, como participante do conselho municipal de saneamento, a gente só é comunicado quando tem a reposição anual de tarifa, o reajuste de tarifa, (...) Com certeza tarifa, tarifa. As pessoas são convocadas prá discutir tarifa, é única e exclusivamente isso, entendeu? [RCO2].

Basicamente de discutir as tarifas... Discutir, vamos dizer, os orçamentos que eram dados [RP].

Em que pese a importância de se discutirem tarifas, constata-se que outros assuntos centrais, como a mudança do controle acionário da Citágua, do Grupo Águia Branca, para a Odebrecht, acontecido em agosto de 2008, ou a extensão dos serviços à área rural não têm sido discutidos no Comusa.

A limitação das pautas ou, ainda, a sensação de que já vêm previamente estabelecidas deixam a impressão de que o processo oculta informações relevantes e de que são estreitas as possibilidades de deliberação. Essa forma de funcionamento pode levar a um ceticismo em relação à participação e à crença de que o conselho serve apenas para endossar decisões sobre as quais há poucas possibilidades de discussão e deliberação. Isso enfatiza a necessidade de que as agendas sejam discutidas previamente para possibilitar que as sugestões sejam mais bem elaboradas, como argumentam Deng e Wu (2010) e Parkinson (2004). 
A interferência política no interior do Comusa também foi comentada por um dos conselheiros e pelo representante da Prefeitura Municipal, como um fator que pode comprometer sua autonomia:

(...) E o que a gente acha mais interessante é que na reunião que tivemos, tava o prefeito de Cachoeiro de Itapemirim, o Castiglione, alguns secretários, e o gerente da Agersa. E as pessoas defendem, entendeu, como se realmente aquilo não pode, tem que ter reajuste mesmo, tem que ter realinhamento econômico [RCO2].

Existe um Conselho Municipal de Saneamento, que ele tá atrelado a essa agência, né? De... regulamentação [RP].

Barth (2006) comenta que, ao mesmo tempo que os municípios estão mais próximos das necessidades da população, também neles as relações sociais são bastante influenciadas por interesses políticos e dependências clientelísticas.

\subsubsection{Falta de informação e de articulação com a sociedade}

Para que haja igualdade de oportunidades, no que se refere à possibilidade de introduzir questões na agenda e aduzir razões contrárias ou favoráveis a determinados assuntos submetidos aos procedimentos deliberativos, a informação é um quesito fundamental (Habermas, 1997). No Comusa, a deficiência de informação foi apontada como fator limitador da igualdade política de participação:

Eu vejo que a falta de informação, principalmente da questão legal, muito grande. O próprio Conselho em si... As atribuições de cada um, o papel de cada um, né? ainda tá... ainda tem que ser mais determinado, mais esclarecido, mais orientado, tá? E isso faz com que... é... vamos dizer, quem hoje tá fazendo a gestão fique mais à vontade. Ou seja: ele tá lidando com o público, ele tá lidando com uma liderança que às vezes não tem conhecimento profundo do verdadeiro papel, da verdadeira ação... [RP].

A questão do acesso à informação vem sendo discutida como fator que limita a função do controle social por parte da sociedade civil nesses espaços uma vez que reduz a possibilidade de argumentação e de influência deliberativa na formulação de propostas (Schönleitner, 2004; Costa, 2001). A falta de visibilidade pública das pautas e decisões do conselho e de articulação deste com a sociedade civil terminam por impossibilitar que esse mecanismo de participação seja, de fato, uma "caixa de ressonância" das demandas sociais. Ressalta-se que a publicidade dos atos do Comusa está prevista na PMS: "Os atos do Comusa são de domínio público e serão amplamente divulgados" (Cahoeiro de Itapemirim, 1999a). Embora na prática essa publicidade não venha acontecendo, essa questão não passa despercebida: 
(...) Eu acho que o Conselho é um espaço que você tem, é um espaço que você tem prá discutir as questões, prá apresentar propostas, as ideias e debater as questões e alertar a própria sociedade, né? Mas, infelizmente, nesse caso aqui, ineficiente, não tá aí colocando, não tá cumprindo os seus objetivos que deveria de ser [RCO2].

\subsubsection{Possibilidades democráticas do Comusa}

Apesar dos limites e constrangimentos do funcionamento do Comusa, há também a crença em suas possibilidades de deliberação democrática e o reconhecimento da sua importância para a política e gestão do saneamento:

Quanto ao Conselho, o Conselho eu acho extremamente importante, porque eu acho que o Conselho é um espaço que você tem, é um espaço que você tem prá discutir as questões, prá apresentar propostas, as ideias e debater as questões e alertar a própria sociedade, né? [RCO2].

É... prá poder ajudar a gerir, ver suas opiniões, seus movimentos... É... o movimento, levar o que o povo está sentindo para dentro desses Conselhos pra poder chegar até o governo [RF].

Na discussão sobre o conflito entre tecnoburocracia e tecnodemocracia, presente no Orçamento Participativo, Santos (2005:540) comenta, em suas observações de campo, a profunda aprendizagem de comunicação e argumentação com cidadãos comuns: "assisti a muitos debates vivos entre moradores e engenheiros acerca da pavimentação, da localização dos canos de esgoto etc. e fiquei impressionado com a capacidade de argumentação das comunidades".

\subsection{A participação nas audiências públicas da Agersa}

A estrutura organizacional e atribuições da Agersa estão definidas em Lei, estabelecendo como sua finalidade principal promover a regulação, o controle e a fiscalização dos serviços públicos concedidos pelo poder público. Como mecanismos de articulação com a sociedade, estão previstas pelo menos duas audiências públicas a cada ano, para demonstração do desempenho da prestação do serviço pelo ente regulado (Cachoeiro, 1999b). No entanto, assuntos importantes, como a mudança no controle acionário da concessionária, não foram discutidos na audiência que a sucedeu, embora já fosse do conhecimento da Agersa. No entendimento do representante da Agersa: "Esse é um assunto a ser discutido no Conselho Administrativo de Defesa Econômica (Cade)".

O representante da Agersa alega falta de interesse da população em sua participação nas audiências, apesar dos convites a toda a sociedade civil, instituições e órgãos locais e uma ampla divulgação na mídia. 
Não há uma participação popular muito efetiva, tanto que acho que tem que se fazer... vamos começar a fazer um trabalho de aproximação com a população, no sentido de criar uma ambiência, um clima de participação, seja fazendo palestra nos centros universitários, nas faculdades, nas escolas de educação básica e infantil [RA].

Constatou-se que, em média, apenas 14 pessoas participaram das duas Audiências Públicas realizadas no ano de 2008 e eram predominantemente procedentes da própria Agersa e da Citágua (Foz do Brasil). A falta de discussão prévia dos assuntos junto à sociedade civil foi ressaltada pelo representante do Conselho de Saúde como um fator que desmotiva a participação social:

É um instrumento eu acho que superado. (...) Eu acho que pro poder dar crédito a um tipo de discussão desse, ao invés de fazer o debate, abrir um canal de debate na prestação de conta, você deveria de, antes de efetuar, fazer o debate pra discutir com a população. Pra população ver o que quer, o que precisa e o que não precisa. Aí sim, aí depois de efetivado, fazer a prestação de conta. Agora você levar pra prestar conta uma coisa que você não debateu e não discutiu com a sociedade, fica difícil mobilizar [RCS].

Na prática, o que se constata é que as audiências não vêm se constituindo em espaços de diálogo, discussão e deliberação, reduzindo-se ao seu caráter legal e obrigatório de prestação de contas, tornando-se espaço para referendar e homologar decisões e relatórios.

\subsection{A participação da população nas esferas públicas autônomas}

Na formulação concreta do modelo de democracia de Habermas (1997), a formação da opinião e da vontade segue duas vias que devem estar articuladas: as informais e as institucionais.

Falou-se até aqui dos espaços institucionalizados de participação das políticas de saneamento. Os espaços informais de participação, próprios da esfera pública, são também decisivos para a democracia deliberativa, pois são o substrato necessário ao debate público. Em relação a eles, constatou-se, nas expressões dos grupos focais em geral, a pequena participação dos cidadãos, nas associações de moradores ou de outras organizações de interesse coletivo. Os motivos alegados são, entre outros, a preocupação com problemas cotidianos individuais e acentuada ênfase na falta de informação:

Eu só queria completar uma coisinha (...) O que que tá acontecendo? Não sei se vocês concordam comigo. O que tá acontecendo com eles? Todos estão sobrecarregados. É família. É trabalho. É situação financeira. É tudo. Então a gente não tá nem aí, se preocupando... [P3P2].

Eu acho que um pouco de falta de informação de quem promove, porque não existe na realidade interesse para que a comunidade participe... [P1GC2]. 
Falta de interesse. Porque nós mesmos, da área da saúde, quando a gente faz alguma palestra, relacionada à saúde, a gente convida a comunidade, vai de casa em casa, corre atrás, mas, se vêm três ou quatro, é muito. [PGC1].

Essa omissão, apatia ou aversão à participação não pode ser atribuída somente a um ato da vontade, mas à colonização do mundo da vida, se levarmos em conta a teoria da ação comunicativa (Habermas, 2010). Os mecanismos do mercado, por meio do controle da mídia, por exemplo, transformam o cidadão em cliente que não consegue se ver como criador da esfera pública, mas como criatura, mercê da dádiva da burocracia estadual (Pinto, 1996), incapaz de compreender as políticas públicas, de saneamento, por exemplo, como direito.

Observou-se que a população, principalmente dos bairros carentes, utiliza bastante a mídia local (rádio e televisão) quando deseja denunciar seus problemas e reivindicar soluções relativas aos serviços de água e esgoto. Uma forma pontual, individual e não articulada com os mecanismos formais, revelando um descrédito nas instituições e tendo ainda como premissa a solução mais imediata de suas necessidades.

Pra te falar a verdade, a gente procura meios e meios e não consegue. Então o único meio que alguns aqui acham que é o meio ideal é colocar a boca no mundo. Igual colocaram agora essa semana... Chamaram a TV, mostraram, filmaram... É o que o povo tá fazendo [P3GC1].

Hoje aqui em Cachoeiro de Itapemirim nós temos uma rádio, aonde pessoas assim, particulares, sentem um problema, vai pra rádio, denuncia e a rádio vai lá com a sua reportagem e procura informação... da empresa... procura o que tem de direito... e tenta trazer resposta... Então, a reportagem da rádio faz, mas é isoladamente, o povo ainda não aprendeu que ele tem que se unir, e pra ver se as empresas um dia busque o povo pra tomar a decisão[P5GC2].

A política local é ainda muito centralizadora e não propicia oportunidades de participação. O perfil político do município mostra, na opinião dos entrevistados, fortes traços populistas e autoritários.

Ditadura. Cê conhece a ditadura né? Só sabe das coisas que está fazendo, depois (...), certamente na época da Citágua não houve isso, nós não pudemos opinar. O prefeito determinou e foi assim... [P1GC2].

Olha eu acho que a nossa cidade de Cachoeiro de Itapemirim ela ainda é muito... é um poder se detém muito na mão lá do... centralizado... O poder ta lá. (...) o povo ainda não entendeu... não existe nenhum canal pra isso não [P6P2].

Isto pode ser corroborado ainda no depoimento do representante da Prefeitura:

A gente tem certeza de que o que aconteceu em Cachoeiro, o que acontece hoje a nível de Estado, tá? são ideias, sabe? dos governantes. São modelo de gestões, vamos questionar: alguns são efi- 
cientes e outro não, mas que tem no seu bojo um controle, tá? Um controle político, um controle econômico, né? e... vamos dizer... e os interesses aí vão se perpetuando no processo, tá?[RP].

Como salientam Tenório e Marques Filho (2006:117), os traços da cultura da política na América Latina, e em particular no Brasil, são ainda "fomentados pelo 'clientelismo', 'compra de votos', 'clientelismo político', 'coronelismo', 'fisiologismo' e outros ismos que adjetivam negativamente a política nacional assim como as sub-regionais". Estes traços reproduzem-se no mundo da vida, como um tipo de colonização, podendo ser observado no relato de um participante do grupo focal do bairro Gilson Carone, em relação ao processo de eleição para a presidência da associação de moradores:

A questão do bairro é o seguinte: aquele que se candidata a presidente, o que ganha é porque compra, entendeu? A maioria que é adolescente que tem 16 anos é que tem direito a votar pra presidente de bairro. O que que eles fazem? Eles põem um barzinho, um pagodinho, libera uma carne assada e aquele negócio todo, compra. Porque é muito adolescente no nosso bairro. Só os votos dos adolescentes consegue eleger um presidente aqui [P3GC1].

A conexão entre as instâncias institucionais, como o Comusa e as audiências públicas da Agersa, e os espaços autônomos de "conversação cívica" não vem acontecendo. Constatase que tanto os temas originados nesses espaços públicos, de forma ainda precária, não têm sido levados e discutidos no Comusa, como também os assuntos ali discutidos não são trazidos ao conhecimento das associações de moradores. Assim, não há a constituição de uma esfera pública com atuação política e com o status normativo de um órgão de mediação entre a sociedade e o poder estatal, nos moldes da proposta de Habermas (1997).

\section{Considerações finais}

Buscou-se com este estudo analisar como se dão os processos de participação social na gestão dos serviços de água e esgotos do muncípio de Cachoeiro de Itapemirim. Como discutido, o município possui uma Política Municipal de Saneamento, que prevê importantes instrumentos de participação, como o Comusa e as audiências públicas da Agersa. No entanto, o que se pôde constatar é que ainda se trata de uma "política de papel", já que seu funcionamento não vem sendo irrigado a partir de discussões trazidas das esferas públicas formadas pela sociedade civil.

Antes, esses instrumentos têm se prestado predominantemente para referendar interesses burocráticos e legais de acompanhamento do contrato de concessão. Isto pôde ser constatado pelo fato de que o conselho vem funcionando com representação assimétrica, já que em sua maioria é composto por representantes do governo, sua pauta é restrita e a [des]informação compromete a participação. O Comusa, que poderia se constituir num espaço público importante para a gestão democrática do saneamento, passa a ter um fun- 
cionamento permeado pelos constrangimentos sistêmicos (poder e dinheiro). As audiências públicas da Agersa, que serviriam para esclarecer e prestar contas dos serviços de saneamento à população, têm cumprido mera formalidade legal obrigatória.

Embora reconheçam a importância da participação, os entrevistados relatam que as instâncias ainda são muito deficientes. A ausência da sociedade civil na formulação, acompanhamento e controle da gestão dos serviços de abastecimento de água e esgoto pode trazer prejuízos à coletividade, muitas das vezes não percebidos de forma clara. Esses podem ser traduzidos na malversação dos recursos, iniquidade na sua aplicação, falta de adesão aos serviços, entre outros.

As possibilidades de participação na formulação e acompanhamento da gestão do saneamento no município de Cachoeiro estão dadas considerando-se que instâncias de participação estão disponíveis do ponto de vista institucional. No entanto, vistas as limitações para sua efetivação, necessário se faz resgatar a proposta de esfera pública trazida pela teoria habermasiana. Descrita como uma rede adequada para a comunicação de conteúdos, nela, questões relevantes como as relativas ao saneamento poderiam ser discutidas, com igual oportunidade de que todos pudessem expressar suas opiniões, sugestões e propostas.

A crise dos serviços de abastecimento de água e esgotos, vivenciada no município de Cachoeiro de Itapemirim, materializada pela falta d'água, e que culminou com a privatização dos serviços em 1998, provavelmente não se resolverá somente com o retorno da água à torneira. Embora do ponto de vista das necessidades imediatas tenha sido essencial, estão em jogo relações que implicam uma participação ativa da sociedade na construção de uma política de saneamento que atenda aos princípios de equidade, universalidade e ao seu caráter de direito social.

Em realidades como a brasileira, que se reflete no município de Cachoeiro de Itapemirim e se expressa em um quadro de desigualdades sociais, pensar em igualdade de direitos entre desiguais, como requerem os processos deliberativos, pode soar utópico.

No entanto, embora a gestão do saneamento em Cachoeiro de Itapemirim ainda esteja distante do modelo discursivo habermasiano, e o cidadão ainda seja reduzido, quando muito, a um cliente, acredita-se que os espaços institucionais, como o Comusa e as audiências públicas, possam se vincular aos processos de organização e mobilização da sociedade civil. Essa, organizada em espaços autônomos, como as associações de moradores, pode gerar debates sobre temas relevantes para a política municipal de saneamento, que poderão ser levados às instâncias formais, conectando-as em processos de deliberação.

\section{Referências}

AGÊNCIA MUNICIPAL DE REGULAÇÃO DOS SERVIÇOS PÚBLICOS DELEGADOS (Agersa). Sétimo termo aditivo ao contrato de concessão n. 029/98, 2006. Disponível em: <www.agersa.com. br/default/attachments/061_7..0\%20Termo\%20Aditivo\%20Contrato\%20Concessão.pdf>. Acesso em: 11 mar. 2009. 
ALOCHIO, Luiz H. A. Direito do saneamento: introdução à lei de diretrizes nacionais de saneamento básico (Lei Federal no 11.445/2007). Campinas: Millennium, 2007.

AVRITZER, Leonardo. Modelos de deliberação democrática: uma análise do orçamento participativo no Brasil. In: SANTOS, Boaventura S. (Org.). Democratizar a democracia: os caminhos da democracia participativa. 3. ed. Rio de Janeiro: Civilização Brasileira, 2005. p. 561-597.

AVRITZER, Leonardo. Prefácio. In: MARQUES, Ângela. C. S. (Org. e trad.). A deliberação pública e suas dimensões políticas comunicativas: textos fundamentais. Belo Horizonte: Autêntica, 2009. p.7-10.

BARTH, Jutta. Public policy management councils in Brazil: how far does institutionalized participation reach? Public Administration and Development, v. 26, n. 3, p. 253-263, Jul. 2006.

BATISTA, Elizabeth C. Saúde é democracia? Experiência da participação popular em Ipatinga. Dissertação (mestrado em saúde pública) — Faculdade de Medicina, Universidade Federal de Minas Gerais, Belo Horizonte, 2005.

BATISTA, Elizabeth C.; MELO, Elza M. A participação popular em Ipatinga-MG, Brasil: conquistas e desafios do setor saúde. Ciência Saúde Coletiva, v. 16, n. 1, p. 337-347, jan. 2011.

BOHMAN, James. O que é a deliberação pública? Uma abordagem dialógica. In: MARQUES, Ângela Cristina S. (Org. e trad.). A deliberação pública e suas dimensões políticas comunicativas: textos fundamentais. Belo Horizonte: Autêntica, 2009. p. 31-84.

BRASIL. Congresso Nacional. Lei no 11.445 , de 5 de janeiro de 2007. Estabelece diretrizes nacionais para o saneamento básico. Disponível em: <www.planalto.gov.br/ccivil_03/_ato2007-2010/2007/ lei/111445.htm>. Acesso em: 15 fev. 2008.

BRITTO, Ana Lúcia. N. P. Gestão de serviços de saneamento em áreas metropolitanas: as alternativas existentes diante da necessidade de universalização dos serviços e preservação da qualidade ambiental. In: ENCONTRO ANUAL ASSOCIAÇÃO NACIONAL DE PÓS-GRADUAÇÃO E PESQUISA EM AMBIENTE E SOCIEDADE, 2., 2004, Indaiatuba. Anais... Indaiatuba. Disponível em: <www. anppas.org.br/encontro_anual/encontro2/GT/GT11/ana_britto.pdf>. Acesso em: 2 set. 2006.

CACHOEIRO DE ITAPEMIRIM. Decreto no 17.253 de 13 de fevereiro de 2007. Dispõe sobre a composição do Conselho Municipal de Saneamento. Disponível em: <http://leis.cachoeiro.es.gov. br:8081/images/leis/html/D172532007.html>. Acesso em: 22 mar. 2009.

CACHOEIRO DE ITAPEMIRIM. Lei no 4.797 de 14 de julho de 1999a. Dispõe sobre a política de saneamento, seus instrumentos e dá outras providências. Disponível em: < http://leis.cachoeiro. es.gov.br:8081/>. Acesso em: 28 maio 2008.

CACHOEIRO DE ITAPEMIRIM. Lei no 4.798 de 14 de julho de 1999b. Cria a agência municipal de regulação dos serviços de saneamento de Cachoeiro de Itapemirim e dá outras providências. Disponível em: <http://leis.cachoeiro.es.gov.br:8081/images/leis/html/ L47981999.html>. Acesso em: 22 mar. 2009. 
CACHOEIRO DE ITAPEMIRIM. Lei no 5.807 de 29 de dezembro de 2005. Institui e define a estrutura organizacional da Agersa, cria e extingue cargos de provimento em comissão e dá outras providências. Disponível em: <http://leis.cachoeiro.es.gov.br:8081/images/leis/html/L58072005.html\#a22> . Acesso em: 8 jun. 2009.

CASTRO, José E.; LACABANA, Miguel. Agua y desarrollo en América Latina: por una democracia sustantiva en la gestión del agua y sus servicios. Cadernos del Cendes, v. 22, n. 59, p. 1-2, mayo 2005.

CITÁGUA. Proposta para o Prêmio Nacional de Qualidade em Saneamento PNQS — Nível II, 2008.

COSTA, Vanda Maria R. C. Teoria democrática e conselhos de política social. In: BRAVO, Maria Inês S.; PEREIRA, Potyara A. P. (Org.). Política social e democracia. São Paulo: Cortez, 2001. p. $87-111$.

COSTA, Marco Aurélio B. Cachoeiro: referência nacional em saneamento. Cachoeiro de Itapemirim: Citágua, 2005.

DAGNINO, Evelina. Sociedade civil, participação e cidadania: de que estamos falando? In: MATO, Daniel (Coord.). Políticas de ciudadanía y sociedad civil en tiempos de globalización. Caracas: Faces, Universidad Central de Venezuela, 2004. p. 95-110.

DELLA PORTA, Donatella. Deliberation in movement: why and how to study deliberative democracy and social movements. Acta Politica, v. 40, n. 3, p. 336-350, 2005.

DENG, Chung-Yeh; WU, Chia-Ling. An innovative participatory method for newly democratic societies: the "civic groups forum" on national health insurance reform in Taiwan. Social Science \& Medicine, v. 70, n. 6, p. 896-903, 2010.

FISHKIN, James S. et al. Deliberative democracy in an unlikely place: deliberative polling in China. British Journal of Political Science, v. 40. n. 2, p. 435-448, Jan. 2010.

FUNG, Archon. Varieties of participation in complex governance. Public Administration Review, v. 66, S1, p. 66-75, Dec. 2006.

FUNG, Archon; WRIGHT, Erik. O. Deepening democracy: innovations in empowered participatory governance. Politics \& Society, v. 29, n. 1, p. 5-41, Mar. 2001.

GASKELL, George. Entrevistas individuais e grupais. In: BAUER, Martin W.; GASKELL, George (Ed.). Pesquisa qualitativa com texto, imagem e som: um manual prático. Tradução de Pedrinho A. Guareschi. Petrópolis: Vozes, 2002. p. 64-89.

GOHN, Maria da Glória. Conselhos gestores e gestão pública. Ciências Sociais Unisinos, v. 42, n. 1, p. 5-11, jan./abr. 2006.

GRÖNLUND, Kimmo; SETÄLA, Maija; HERNE, Kaisa. Deliberation and civic virtue: lessons from a citizen deliberation experiment. European Political Science Review, v. 2, n. 1, p. 95-117, Feb. 2010.

GUTMANN, Amy; THOMPSON, Dennis. O que significa democracia deliberativa? Revista Brasileira de Estudos Constitucionais - RBEC, Belo Horizonte, ano 1, n. 1, p. 17-78, jan./mar. 2007. 
HABERMAS, Jürgen. Comunicação política na sociedade mediática: o impacto da teoria normativa na pesquisa empírica. Líbero, São Paulo, ano XI, n. 21, p. 9-20, jun. 2008.

HABERMAS, Jürgen. Direito e democracia: entre facticidade e validade. Rio de Janeiro: Tempo Brasileiro, 1997. v. 2.

HABERMAS, Jürgen. Teoria de la acción comunicativa: racionalidad de la acción. Tomo I: Racionalización social; Tomo II: Crítica de la razón funcionalista. 4. ed. Tradução de Manuel Jiménez Redondo. Madri: Trotta, 2010.

HELLER, Léo; CASTRO, José E. Política pública de saneamento: apontamentos teórico-conceituais. Revista de Engenharia Sanitária, v. 12, n. 13, p. 284-295, jul./set. 2007.

HELLER, Léo; REZENDE, Sonaly C. B. L.; HELLER, Pedro G. B. Participação e controle social em saneamento básico: aspectos teórico-conceituais. In: GALVÃO JÚNIOR, Alceu C.; XIMENES, Marfisa Maria A. F. (Ed.). Regulação: controle social da prestação dos serviços de água e esgoto. Fortaleza: Pouchain Ramos, 2007. p. 37-68.

INSTITUTO BRASILEIRO DE GEOGRAFIA E ESTATÍSTICA (IBGE). Censo Demográfico 2010. Disponível em: <www.ibge.gov.br/home/estatistica/populacao/censo2010/resultados_dou/ES2010. pdf>. Acesso em: 15 jun. 2012.

INSTITUTO JONES DOS SANTOS NEVES (IJSN). Índice de carência em saneamento básico — 2000. Espírito Santo, 2004.

JACOBI, Pedro; PINHO, José Antonio (Org.). Inovação no campo da gestão pública local: novos desafios, novos patamares. Rio de Janeiro: Editora FGV, 2006.

LÜCHMANN, Ligia Helena H. Possibilidades e limites da democracia deliberativa: a experiência do Orçamento Participativo de Porto Alegre. Tese (doutorado em ciências sociais) — Instituto de Filosofia e Ciências Humanas, Universidade Estadual de Campinas, Campinas, 2002.

MACEDO, Elizabeth F. Pensando o currículo e a escola à luz da teoria de J. Habermas. Em Aberto, Brasília, ano 12, n. 58, p. 38-44, abr./jun. 1993.

MARQUES, Ângela Cristina S. As interseções entre o processo comunicativo e a deliberação pública. In: MARQUES, Ângela Cristina S. (Org. e trad.). A deliberação pública e suas dimensões políticas comunicativas: textos fundamentais. Belo Horizonte: Autêntica Editora, 2009. p. 11-28.

MELO, Elza M. et al. A organização da Atenção Básica em municípios integrantes do projeto de expansão e consolidação do saúde da família em Mato Grosso, Brasil. Cadernos de Saúde Pública, v. 24, supl. 1, p. s29-s41, 2008.

MINAYO, Maria Cecília. O desafio do conhecimento: pesquisa qualitativa em saúde. 10. ed. Rio de Janeiro: Hucitec, 2006.

NEBLO, Michael. Thinking through democracy: between the theory and practice of deliberative politics. Acta politica, v. 40, n. 2, p. 169-181, Sept. 2005.

PARKINSON, John. Why deliberate? The encounter between deliberation and new public managers. Public administration, v. 82, n. 2, p. 377-395, Jun. 2004. 
PINTO, José M. R. Administração e liberdade: um estudo do conselho de escola à luz da teoria da ação comunicativa de Jürgen Habermas. Rio de Janeiro: Edições Tempo Brasileiro, 1996.

REZENDE, Sonaly Cristina B. L.; HELLER, Léo. O saneamento no Brasil: políticas e interfaces. 2. ed. rev. e aum. Belo Horizonte: Editora UFMG, 2008.

RIST, Stephan et al. Moving from sustainable management to sustainable governance of natural resources: the role of social learning processes in rural India, Bolivia and Mali. Journal of Rural Studies, v. 23, n. 1, p. 23-37, jan. 2007.

SANTOS, Boaventura S.; AVRITZER, Leonardo. Para ampliar o cânone democrático. In: SANTOS, Boaventura S. (Org.). Democratizar a democracia: os caminhos da democracia participativa. 3. ed. Rio de Janeiro: Civilização Brasileira, 2005. p. 39-77.

SCHÖNLEITNER, Günther. Can public deliberation democratise state action? Municipal health councils and local democracy in Brazil. In: HARRISS, John; STOKKE, Kristian; TÖRNQUIST, Olle (Ed.). Politicising democracy: the new local politics of democratization. Basingstoke: Palgrave Macmillan, 2004. Disponível em: <www.uio.no/studier/emner/sv/iss/SGO2400/h05/undervisningsmateriale/Schonleitner.pdf > . Acesso em: 22 set. 2011.

TATAGIBA, Luciana. Os conselhos gestores e a democratização das políticas públicas no Brasil. In: DAGNINO, Evelina. Sociedade civil e espaços públicos no Brasil. São Paulo: Paz e Terra, 2002. p. 47-105.

TENÓRIO, Fernando G.; MARQUES FILHO, Humberto. Cidadania deliberativa: um estudo de caso. In: TENÓRIO, Fernando G. (Org.). Cidadania e desenvolvimento local. Rio de Janeiro: Unijuí, 2006. p. $99-118$.

THIOLLENT, Michel J. M. Crítica metodológica, investigação social e enquete operária. 5. ed. São Paulo: Polis, 1987.

THOMASSEN Lasse. Habermas: a guide for the perplexed. Londres: Continuum International Publishing Group, 2010.

VIERO, Odete M. Water supply and sanitation in Porto Alegre - Brazil. In: CONFERENCIA INTERNACIONAL PRINWASS PRIVATE PARTICIPATION IN WATER AND SANITATION: TOOLS FOR EXPLORING AND EVALUATING CURRENT POLICIES IN THE SECTOR, 2, 2003, México. Disponível em: <http://prinwass.ncl.ac.uk/PDFs/DMAE.PDF>. Acesso em: 22 abr. 2009.

VIZEU, Fabio; BIN, Daniel. Democracia deliberativa: leitura crítica do caso CDES à luz da teoria do discurso. Revista de administração Pública - RAP, Rio de Janeiro. v. 42, n. 1, p. 83-108, jan./fev. 2008.

Marluce Martins de Aguiar é doutora em saneamento, professora do Instituto Federal do Espírito Santo (Ifes), Coordenadoria de Saneamento Ambiental. E-mail: marluce@ifes.edu.br. 
Léo Heller é doutor em epidemiologia, pós-doutorado na Universidade de Oxford, professor titular do Departamento de Engenharia Sanitária e Ambiental da Universidade Federal de Minas Gerais (UFMG). E-mail: Heller@desa.ufmg.br.

Elza Machado de Melo é doutora em medicina preventiva e professora do Departamento de Medicina Preventiva e Social da Faculdade de Medicina da UFMG. E-mail: elzamelo@medicina.ufmg.br. 
